\title{
A new fossil lacewing genus and species from the Middle Jurassic of Inner Mongolia, China
}

Yongjie Wang, Zhiqi Liu, and Dong Ren

Acta Palaeontologica Polonica 54 (3), 2009: 557-560 doi: http://dx.doi.org/10.4202/app.2008.0040

A new fossil lacewing, Tenuosmylus brevineurus gen. et sp. nov., was collected from an outcrop of Middle Jurassic strata in the village of Daohugou, Inner Mongolia, China. The new genus is assigned to Gumillinae based on eleven defining characteristics of the subfamily. The affiliation of Tenuosmylus including other five genera of the subfamily is discussed. Our result supports the opinion that Epiosmylinae was a junior synonym of Gumillinae, which is likely a relic of ancient osmylids based on similarity of forewing venation. Veins $\mathrm{Mp}_{2}$ and $\mathrm{Cu}_{2}$ have complicated branches that are generally present in extinct as well as some extant subfamilies (Poriminae, Eidoporisminae, Stenosmylinae). A key is given to differentiate six known genera within Gumillinae.

Yongjie Wang [wangyjosmy@yahoo.cn] and Zhiqi Liu [zhiqiliu@ cau.edu.cn], Department of Entomology, China Agricultural University, 2

uanmingyuanxilu, Beijing 100193, China; Dong Ren [rendong@mail.cnu.edu.cn] (corresponding author), Department of Biology, Capital Normal University, 105 Xisanhuanbeilu, Beijing 100048, China

This is an open-access article distributed under the terms of the Creative Commons Attribution License (for details please see creativecommons.org), which permits unrestricted use, distribution, and reproduction in any medium, provided the original author and source are credited. 